\title{
Innovation of New Fibre-Girardinia Heterophylla
}

\author{
T. Vijayalakshmi and Dr.G. Manonmani
}

\begin{abstract}
The common name of Girardinia Heterophylla is Nettle. It is found in the tropical regions like Nilgiris and Anamalai Hills and Himalayas. Clothing made from Nettles has been worn by the people for the last 2000 years. During $16^{\text {th }}$ century cotton arrived due to which the nettle lost their popularity because cotton was easier to harvest and spin. The Nettle fiber was collected under the foothills of Nilgiris and the fiber is extracted through the process of water retting. The fibers were opened and cleaned for the removal of impurities. The fiber is tested for the following properties - the linear mass density, breaking strength and elongation.
\end{abstract}

Keywords--- Collection, Extraction, Nettle, Testing

\section{INTRODUCTION}

$\mathrm{T}$ HE common name of Girardinia Heterophylla is Nilgiri Nettle. It is found in the tropical regions like Nilgiris and Anamalai Hills and Himalayas. The virulent stinging hairs made the plant as the despised plant in the hills of North India. The plant grows to heights of 3 or 4 feet and is often used as fencing to keep out cattle. The popular Hindi name is Bichuaa means scorpion.Stinging Nettle is a perennial plant found in temperate and tropical wasteland areas. The plant is characterized by pointed leaves and white to yellowish flowers. Clothing made from Nettles has been worn by the people for the last 2000 years. During $16^{\text {th }}$ century cotton arrived due to which the nettle lost their popularity because cotton was easier to harvest and spin. During the first world war there was a shortage in cotton. So, Nettles were used to produce German army uniforms.

Nettle fiber have been used since the Bronze Age to weave sails for boats sand mesh fabrics for shifting flours and filtering honey. The fabrics made of nettle are softer than cotton and the fibers are finer than hemp. Cotton growers resort to using chemicals and pesticides to protect the plants. Nettles are hardy plants and they do not require any chemicals or pesticides for protection. According to Grieve the German army orders of March, April and May 1918 shows the usage of cloth woven from Nettle fiber. Nettles were cultivated in large scale in Austria. Nettle has been found to be superior to cotton for velvet and plush. Like cotton it can also be dyed and bleached and it tends to be slightly inferior to silk after mercerizing.

\section{Literature Survey}

During the First World War there was a shortage in cotton.

T. Vijayalakshmi, Ph.D Scholar, Department of Costume, Design and Fashion, PSG College of Arts and Science, Coimbatore, India. E-mail:vijiraajcdf@gmail.com

Dr.G. Manonmani, Research Supervisor, Assistant Professor, Department of Home Science, Mother Theresa Women's University, Kodaikanal,India.E-mail:manomurali_jagan@yahoo.com

DOI: 10.9756/IJRAS.8106
So, Nettles were used to produce German army uniforms. The third bastfibre that we should consider is nettle from stinging nettles, briefs Barber (1991). Nettles are widely diffused throughout both tropical and temperate climates though they generally occur where there is considerable moisture either of soil or of climate, views Forbes (1855). John(1988) states that it has been found that nettles have been used as clothing in many cultures. In Nepal The nettle fiber was used to produce fine clothes and sail clothes. Joseph 1924 describes that in the sixteenth and seventeenth century Nettle fibers were used in Scotland for weaving the coarser household napery. According to the views of Jennifer (2010) among many fibrous plants experimented with, the Nettle alone fulfilled all the conditions of a satisfactory source of textile fibre, and it was believed that it would become an important factor in agriculture and in the development of the textile industry. Paul (1882) views that research into nettle textiles is still ongoing today. In Europe there are many projects going on to find the ways to cultivate nettles and use the nettle fibre commercially for textiles or composite materials. According to the views of Frank (1920) cloth made from Nettle fibre was employed in many articles of army clothing.

\section{Methodology}

The study is systematically done in the following stages

i. Collection of Nettle fiber

ii. Extraction of the Nettle fiber

iii. Evaluating the properties of the Nettle Fiber

i. Collection of Nettle Fiber

Nettle is found in the tropical regions like Nilgiris and Anamalai Hills and Himalayas. The Nettle fiber was collected in the foothills of Nilgirs. The stem of the plants are cut $10 \mathrm{~cm}$ above the ground. The leaves are removed from the stems. The barksof the stem is separated from the stem using the knives and peeled completely. The barks of the plant were laid in sunlight for three days to dry and then it was processed biologically.

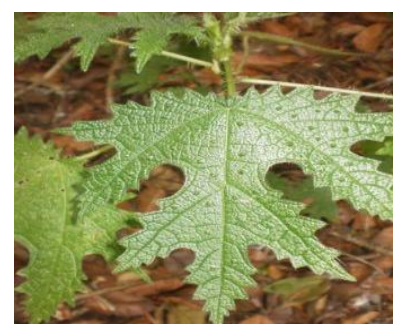

Plate I: Nettle Leaves 


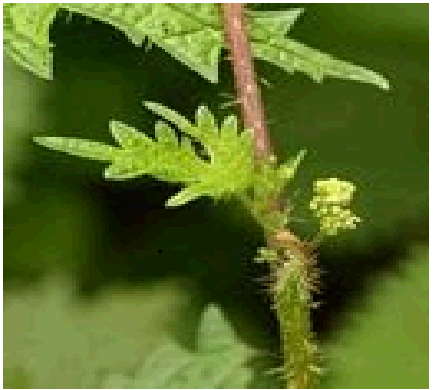

Plate II: Stem of Nettle Plant

\section{ii. $\quad$ Extraction of Nettle Fiber}

Fiber was extracted using water retting method. Water retting process is done to rot away the cellular tissues and gummy substances that surrounds the fiber bundles. Thus facilitates separation of the fiber from the stem. The barks of the plant are placed in the slow stream. Stones are laid over the bark to restrict movement of the bark. This process was continued for about 15 days.

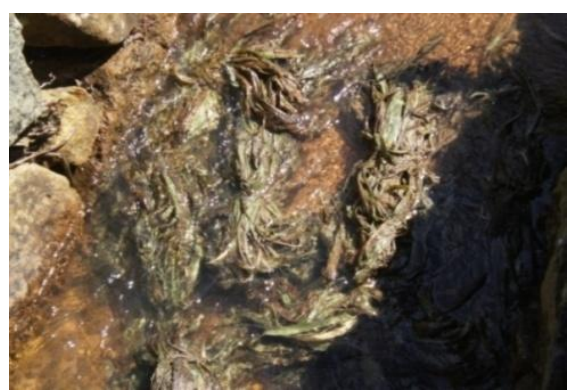

Plate III: Running Water Retting

The retted bark was taken out and beaten with wooden hammer and washed thoroughly to remove the impurities. The fiber is taken and boiled with ash for smoothening of the fibers after which the clean fiber is taken and dried thoroughly.

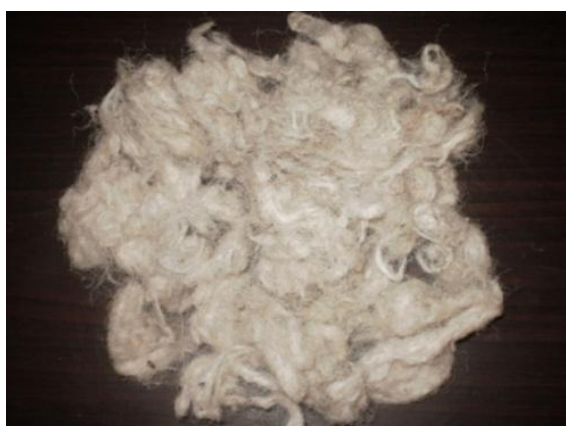

Plate IV: Nettle Fibers

Hard lumps of the fiber are disentangled and loosened by fiber opening process. The fibers were fed into opening machine which passes through rollers with metal hooks which opens the clusters of fibers and separates the fibers. Cleaning was done to remove the trash such as dirt and burrs. Since the natural fiber has a lot of impurities, it is necessary to clean them. Now the fiber is clean and ready to use for further process.

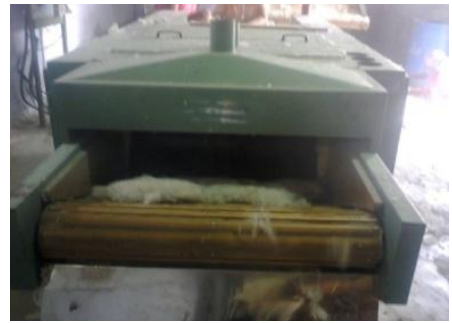

Plate V: Opening and Cleaning Machine

\section{iii. Evaluating the Properties of the Nettle Fiber}

The fibers are tested for the following characteristics

1. Linear Mass Density of a Nettle fiber.

2. Strength of the single fiber.

3. Elongation of the single fiber.

\section{Linear Mass Density}

The linear mass density refers to the mass in grams per 9000 meters. Denier is the unit measure of Linear Mass density.

\section{Strength of the Fiber}

The Breaking Strength measures the resistance of a material to failure, given by applied stress (or load per unit area). Strength of the fiber is found using Instron machine.

\section{Elongation of the Fiber}

Elongation measures the percentage change in length before fracture. Elongation of the fiber is found using Instron machine.

\section{RESULTS AND DISCUSSION}

The results of the study is as follows

\section{Linear Mass Density of Nettle Fiber}

\begin{tabular}{|c|c|}
\hline S.NO & FIBER DENIER \\
\hline 1 & 16.38 \\
\hline 2 & 15.82 \\
\hline 3 & 15.97 \\
\hline 4 & 18.18 \\
\hline 5 & 15.96 \\
\hline 6 & 16.32 \\
\hline 7 & 19.08 \\
\hline 8 & 15.75 \\
\hline 9 & 18.63 \\
\hline 10 & 19.14 \\
\hline MEAN & 17.12 \\
\hline
\end{tabular}

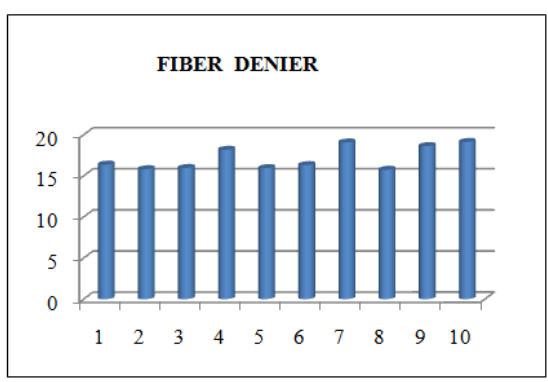

Linear Mass Density of a Nettle fiber is 17.12 Denier 
Strength and Elongation of the Fiber

\begin{tabular}{|l|l|l|l|}
\hline S.NO & $\begin{array}{l}\text { MAXIMUM } \\
\text { LOAD } \\
(\mathrm{gf})\end{array}$ & $\begin{array}{l}\text { TENSILE STRAIN AT } \\
\text { MAXIMUM LOAD } \\
(\%)\end{array}$ & $\begin{array}{l}\text { TENACITY AT } \\
\text { MAXIMUM LOAD } \\
(\mathrm{gf} / \text { den })\end{array}$ \\
\hline 1 & 78.71 & 3.00 & 4.60 \\
\hline 2 & 79.46 & 3.00 & 4.64 \\
\hline 3 & 99.32 & 4.11 & 5.80 \\
\hline 4 & 91.63 & 3.12 & 5.35 \\
\hline 5 & 87.57 & 3.03 & 5.12 \\
\hline 6 & 90.12 & 4.12 & 5.26 \\
\hline 7 & 87.5 & 3.00 & 5.11 \\
\hline 8 & 80.15 & 3.15 & 4.68 \\
\hline 9 & 78.24 & 3.11 & 4.57 \\
\hline 10 & 79.4 & 3.04 & 4.64 \\
\hline MEAN & 85.21 & 3.27 & 4.98 \\
\hline
\end{tabular}

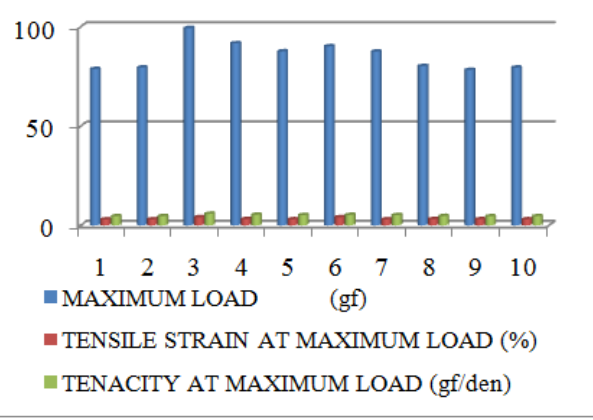

Breaking strength of the single fiber is $85.21 \%$.

Elongation of the single fiber is $3.27 \%$.

\section{CONCLUSION}

The study clears shows the Nettle fiber maybe spun into a yarn and finally woven or knitted into a fabric.

\section{REFERENCE}

[1] Rita Bhusan, "Aweavers garden: growing plants for natural dyes and fibers.", Dover publication, Pp: 42, 1999.

[2] Robert R.Frank, "Bast and other plant fibers", Woodhead Publication

[3] Darcy Williamson, "The Rocky Mountains wild food cookbook", The Caxton Printers, Pp: 178.

[4] Norman K.Risjord, "Shinning Big Seawater: The story of Lake superior", The Minnesota Historical Society press, Pp: 30.

[5] J.Gordon Cook - Handbook of Textile Fibers Vol I, Marrow publication, 1984, Pp: 106

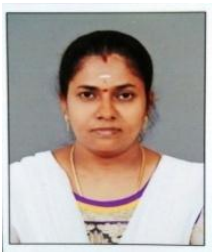

T. Vijayalakshmi was born in Tamilnadu, India. She received her B.Sc degree in Costume Design and Fashion from Bharathidasan College of Arts and Science, Bharathiyar University, Coimbatore, Tamilnadu in 2000. She worked in various Garment industries as Merchandiser in Tamilnadu for 7 years. She received M.Sc Degree in Costume Design and Fashion from Bishop Appasamy College of Arts and Science, Bharathiar University, Coimbatore, Tamilnadu in 2011. She has passed NET exam in 2011. She is having teaching experience for 4 years and currently working as assistant professor in the Department of Garment Designing. She is presently a research Scholar in PSG College of Arts and Science, Bharathiyar University, Coimbatore, Tamilnadu. She has presented many papers in national conferences and published papers in international journals.

Dr.G. Manonmani is graduated from in VVV College, Virudhunagar, Madurai Kamaraj university, in the field of Home science, She received her Master Degree and Master of Philosophy in the field of Textile and Clothing from Avinashilingam Deemed University, Coimbatore and Ph.D. degree from the department of Textiles and Clothing Mother Teresa women's university, Kodaikannal in the field of Design and development of knitted health care textiles for medical applications. She has a teaching experience of 19 years 6months. She published more than 30 research publications, including International Journals, International Conferences, National Conferences, workshops and seminars. She is currently Assistant professor, Dept. of Home science Mother Teresa women's university, Kodaikannal (E-mail: manomurali_jagan@yahoo.com) 